\title{
Uma Investigação sobre o Uso de Ferramentas Computacionais no Ensino de Cálculo Integral e Diferencial
}

\author{
Samantha Chang Rodrigues de Paula, USS, samanthachangr@gmail.com \\ Adriana Maria Balena Tostes, USS, dritostes@yahoo.com.br \\ Gláucia Sabadini Barbosa, USS, galsabadini@yahoo.com.br \\ Marco Antônio Pereira Araújo, USS, marcoaparaujo@gmail.com
}

\begin{abstract}
Resumo: O presente artigo tem o objetivo de apresentar um planejamento metodológico de uma pesquisa que utilizou como objeto de estudo o uso de software no ensino de Cálculo Diferencial e Integral, uma disciplina que tem sido apontada como emblemática no que diz respeito ao aproveitamento acadêmico dos estudantes do Ensino Superior, comprometendo a regularidade do curso e apresentando grande índice de evasão. Nesse sentido, destacam-se alguns trabalhos pesquisados no que tangencia as fragilidades na aprendizagem de conceitos fundamentais como a função matemática. Diante desse cenário, um estudo experimental foi conduzido utilizando ferramentas computacionais escolhidas a partir de um estudo prévio descrito no trabalho, com um conjunto de alunos no sentido de avaliar a utilização dessas ferramentas, através de análise estatística dos dados coletados durante a pesquisa. A pesquisa permitiu apontar dificuldades e potencialidades tanto no espaço de ensino formal quanto no ambiente computacional.
\end{abstract}

Palavras-chaves: Metodologia de ensino, software educacional, ensino e aprendizagem, Cálculo Diferencial e Integral.

Abstract: This paper is intended to provide a methodological planning a survey that used as an object of study the use of software in teaching Differential and Integral Calculus, a discipline that has been claimed as emblematic with regard to the academic achievement of students Higher Education, compromising the regularity of the course and presenting large dropout rate. In this sense, it highlights some papers surveyed in the tangent weaknesses in learning fundamental concepts such as the mathematical function. In this scenario, an experimental study was conducted using computational tools chosen from a previous study described at work with a group of students in order to evaluate the use of these tools, through statistical analysis of data collected during the search. The research allowed pointing difficulties and potentials both in the formal education space and in computing environment.

Keywords: Teaching methodology, educational software, teaching and learning, Differential and Integral Calculus.

\section{Introdução}

Para Amorim (2011), o ensino de Cálculo Integral e Diferencial tem sido muito discutido no âmbito educacional, pelo número elevado de reprovações e desistências nos cursos de Engenharia e áreas afins, tal fato subsidia esse trabalho. Busca-se entender o porquê ou a causa do problema e, consequentemente, pesquisar ações no meio acadêmico que já estejam, de alguma forma, preocupadas com as metodologias adotadas atualmente.

Partindo da tentativa de averiguar esse problema, pesquisou-se o ensino da matemática assistido pela tecnologia computacional como um novo olhar, esse que rompe com conjecturas e passa a ter um esboço da situação. Ao pesquisar sobre as dificuldades dos alunos no ensino de cálculo, constataram-se as dificuldades com a própria linguagem matemática, interpretação das fórmulas e gráficos.

Segundo Rocha (2010), o ensino e aprendizagem de Cálculo Integral e Diferencial tem preocupado, há décadas, professores e pesquisadores em várias partes do mundo. Em nosso país, é significativo o índice de reprovação nessa disciplina nos mais diversos cursos e universidades. Visando a compreender essa situação, estudos têm abordado o problema e 
proposto alternativas. Dentre estas, destaca-se a utilização de software educacional que potencializa a visualização e a experimentação na construção dos conceitos.

Diante do universo informatizado, foi notória a possibilidade de se trabalhar conceitos matemáticos com software educacionais já existentes e gratuitos. Para isso, foi estabelecida a seguinte questão de pesquisa, referente à escolha do ensino no ambiente computacional (Rocha, 2010): que contribuições uma proposta de ensino pautada na articulação entre a visualização e a experimentação, proporcionada pelo ambiente informatizado, pode trazer para a compreensão dos conceitos de limite, derivada e integral em uma disciplina de Cálculo? Para responder essa questão, Borba e Villarreal (2005) esclarecem que diferentes fatores humanos e não humanos constam de um coletivo pensante onde o conhecimento é produzido. Para tanto, o meio computacional torna-se viável e auxilia os processos de ensino e de aprendizagem. Reforçando a ideia, Miskulin et al. (2005) afirmam que o software permite que os alunos construam um conhecimento a partir de exercícios que podem ser desenvolvidos em sala, e os ambientes computacionais são extremamente úteis e importantes para a exploração e construção de conceitos matemáticos, porém ressalta-se que os resultados obtidos dependem muito da intervenção do professor, e de como intervém no processo de ensino e de aprendizagem (Scheller et al., 2014).

Neste trabalho, foi feito um estudo sobre as dificuldades que permeiam a disciplina de Cálculo, foi necessário elaborar um estudo experimental para a realização da pesquisa e, como o objetivo deste trabalho é descrever as etapas, que contou com estudo detalhado para investigar se as estratégias utilizadas, com o uso do computador e suas ferramentas, no ensino de Cálculo, auxiliam na diminuição dos índices de retenção e evasão em diversos cursos do Ensino Superior, julgou-se indispensável legitimar o estudo a partir de procedimentos que contribuem para a realização da pesquisa.

Este artigo é dividido em três seções, além dessa introdução. A seção dois aborda a descrição de uma revisão sistemática da literatura, o critério de escolha do software, elaboração das atividades e aplicação. Na seção três é apresentada a análise dos resultados. $\mathrm{Na}$ quarta seção, apontam-se as considerações finais.

\section{Materiais e Métodos}

A maioria das pesquisas científicas tem seu começo através de uma revisão de literatura executada de forma ad hoc. Entretanto, caso essa revisão não esteja completa e justa, terá pouco valor científico. Essa é a principal razão pela qual se deve considerar o uso de uma revisão sistemática, que é uns dos meios existentes para identificar, avaliar e interpretar a pesquisa pertinente a uma pergunta de pesquisa em particular (Kitchenham, 2004). Além disso, existem outras razões mais específicas que justificam o uso da revisão sistemática (Kitchenham, 2004):

- resumir alguma evidência existente sobre uma determinada teoria ou tecnologia;

- identificar pontos em aberto para a pesquisa em questão, possibilitando a definição de áreas onde mais investigações devem ser realizadas;

- prover um embasamento para novas atividades de pesquisa.

O escopo para aplicação dessa revisão sistemática relaciona-se à utilização de ferramentas computacionais (software), auxiliando no processo de aprendizagem, focando o ensino do Cálculo, mais especificamente, o ensino de Funções.

\subsection{Escolha do software}

O protocolo delimita a área de pesquisa e refina os dados. Atua e organiza de forma sistemática a pesquisa, embasa e justifica todo procedimento.

\subsubsection{Descrição da Revisão Sistemática}

Questão de Pesquisa: Quais são as metodologias, técnicas e ferramentas de apoio ao ensino de Cálculo? 
- Intervenção: trabalhos que apresentem um estudo sobre o uso de ferramentas computacionais como suporte do ensino de Cálculo.

- Controle: não definido.

- Efeito: a partir de experiências relatadas, verificar quais são as metodologias, técnicas e ferramentas que foram utilizadas no ensino de Cálculo.

- Medida de desfecho: quantidade de artigos publicados sobre metodologias, técnicas e ferramentas de apoio ao ensino de Cálculo.

- População: artigos relacionados com metodologia, técnicas e ferramentas de apoio ao ensino de Cálculo.

- Problema: o uso de técnicas e ferramentas computacionais é favorável ao ensino de Cálculo?

- Aplicação: pesquisar as estratégias utilizadas com o uso do computador e suas ferramentas para o ensino de Cálculo

A Tabela 1 apresenta os critérios de inclusão e exclusão para a realização da revisão sistemática a partir da questão de pesquisa apresentada.

Tabela 1. Critérios para a Revisão Sistemática

\begin{tabular}{|l|l|}
\hline \multicolumn{1}{|c|}{ Critério } & \multicolumn{1}{c|}{ Descrição } \\
\hline Seleção de Fontes & $\begin{array}{l}\text { Será fundamentada em bases de dados eletrônicas incluindo as } \\
\text { conferências e artigos listados a seguir. Será considerada também a busca } \\
\text { por proceedings de conferências cuja temática seja o uso de ferramentas } \\
\text { computacionais no ensino de Cálculo. }\end{array}$ \\
\hline Palavras-chave & $\begin{array}{l}\text { Ferramentas computacionais, ensino de Cálculo, atividades, investigação, } \\
\text { relato de experiência, software educacional }\end{array}$ \\
\hline Idioma dos Estudos & Português \\
\hline $\begin{array}{l}\text { Métodos de busca de } \\
\text { fontes }\end{array}$ & $\begin{array}{l}\text { As fontes serão acessadas via web. No contexto dessa revisão não será } \\
\text { considerada a busca manual. }\end{array}$ \\
\hline Listagem de fontes & Google Acadêmico \\
\hline Tipo dos Artigos & Teórico, Prova de conceito, Estudos experimentais. \\
\hline $\begin{array}{l}\text { Critérios de Inclusão } \\
\text { e Exclusão de artigos }\end{array}$ & $\begin{array}{l}\text { Os artigos devem estar disponíveis na web; os artigos devem considerar } \\
\text { estudos do uso de ferramentas computacionais para o ensino de Cálculo. }\end{array}$ \\
\hline
\end{tabular}

\subsubsection{Processo de Seleção dos Estudos Preliminares}

Os pesquisadores aplicaram a estratégia de busca para a identificação de potenciais artigos. Os artigos identificados foram selecionados pelos mesmos pesquisadores através da leitura e verificação dos critérios de inclusão e exclusão estabelecidos. Feito isto, foram selecionados os artigos:

- Avaliação da Qualidade dos Estudos Primários: não foi definido um checklist para a avaliação da qualidade dos artigos. A abordagem para definição da qualidade está fundamentada na fonte para extração do material e na aplicação dos critérios de inclusão e exclusão dos estudos;

- Estratégia de Extração de Informação: para cada estudo selecionado após a execução do processo de seleção, foram extraídos os seguintes dados: Título do artigo; Autores; Fonte; Tipo de artigo; Categoria; Contexto e tecnologia da aplicação; Descrição das metodologias utilizadas;

- Sumarização de Resultados: os resultados foram tabulados e foram realizadas análises para obter os materiais que expliquem as técnicas utilizadas no ensino de Cálculo, no ambiente interação tecnológica;

- Busca: foi necessário restringir o escopo das buscas, essa restrição varia de acordo com a string de busca (uma string de busca é utilizada para pesquisa em bibliotecas digitais, usando-se palavras chaves) utilizada e considera o periódico no qual a busca é realizada e o local onde as palavras chave serão procuradas (todo o texto ou abstract). A string de busca utilizada para a questão de pesquisa apresentada foi: ("ferramenta 
computacional" OR "software educacional") + ("ensino do cálculo" OR "ensino no cálculo" OR "ensino de cálculo" OR "ensino para o cálculo") + ("atividade" OR "laboratório" OR "oficina" OR "investigação" OR "experimento").

\subsubsection{Busca Realizada}

Como resultado da busca realizada no Google Acadêmico, única máquina de busca disponível no momento da pesquisa, definido na lista de fontes dos critérios para realização da Revisão Sistemática, foram encontrados 51 resultados que, após aplicados os critérios de inclusão e exclusão, 24 artigos foram selecionados, e estão apresentados em um protocolo.

Feito o levantamento de ferramentas encontradas nos trabalhos foram utilizados alguns critérios para a avaliação de software, segundo Gonçalves (2010):

- apresentação clara de objetivos e indicação das possibilidades de uso;

- adequação ao equipamento disponível nos respectivos ambientes de ensino;

- facilidade de instalação e desinstalação;

- interativo em relação a diferentes opções de manuseio;

- oferecimento de recursos multimídias;

- fornecimento de manual de utilização;

- compatibilidade e integração com outros softwares e hardware;

- layout que facilite a utilização do software;

- atualização de conteúdo via Internet.

Depois de feita tal análise, foram selecionados cinco softwares para uma análise mais completa: Geogebra (2015), Winplot (2015), Grapes (2015), SpeQ Mathematics (2015) e Math Mechanixs (2015). A seleção teve, como um critérios adicional de análise, a quantidade de downloads em um site especializado.

A análise desses softwares foi feita utilizando uma atividade que envolvia o estudo de uma função, quando proporcionou várias análises à medida que os recursos oferecidos por eles eram utilizados (Tabela 2).

Tabela 2. Ferramentas computacionais analisadas

\begin{tabular}{|c|c|c|c|}
\hline Software & Funcionalidades & Vantagens & Desvantagens \\
\hline Geogebra & $\begin{array}{l}\text { O GeoGebra reúne recursos de } \\
\text { geometria, funções, álgebra, tabelas, } \\
\text { gráficos, probabilidade, estatística e } \\
\text { cálculos simbólicos em um único } \\
\text { ambiente. }\end{array}$ & $\begin{array}{l}\text { Tem a vantagem didática de } \\
\text { apresentar, ao mesmo tempo, } \\
\text { representações diferentes de } \\
\text { um mesmo objeto que } \\
\text { interagem entre si. Pode ser } \\
\text { usado do ensino fundamental } \\
\text { à universidade. Possui } \\
\text { materiais de apoio gratuitos. }\end{array}$ & $\begin{array}{l}\text { Para saber como usar os } \\
\text { seus comandos, exige um } \\
\text { conhecimento aprofundado } \\
\text { no tema. }\end{array}$ \\
\hline Winplot & $\begin{array}{l}\text { WinPlot apresenta uma quantidade } \\
\text { grande de ferramentas para que o } \\
\text { aluno trabalhe com funções 2D, } \\
\text { com a possibilidade de encontrar } \\
\text { raízes, realizar combinações entre } \\
\text { funções, rotações, comprimentos de } \\
\text { arco, cálculo de volume e área, } \\
\text { animação, etc. } \\
\text { Todos os gráficos podem ser } \\
\text { personalizados, com alteração de } \\
\text { cores de fundo, fontes e tabelas. É } \\
\text { um programa completo e totalmente } \\
\text { em português que facilita a vida de } \\
\text { alunos, visto que é uma ferramenta } \\
\text { educacional simples de utilizar. }\end{array}$ & $\begin{array}{l}\text { As opções de equações estão } \\
\text { bem estruturadas em uma } \\
\text { interface intuitiva. Caso } \\
\text { tenha alguma dificuldade, a } \\
\text { opção de Ajuda aparece em } \\
\text { todas as janelas do programa, } \\
\text { com explicações e definições } \\
\text { que certamente esclarecerão } \\
\text { as suas dúvidas. O WinPlot } \\
\text { além de totalmente gratuito e } \\
\text { encontra-se no idioma } \\
\text { Português, facilitando a } \\
\text { utilização do programa. }\end{array}$ & $\begin{array}{l}\text { Não possui função } \\
\text { "desfazer" para casos em } \\
\text { que gráficos são apagados } \\
\text { por engano. }\end{array}$ \\
\hline
\end{tabular}




\begin{tabular}{|c|c|c|c|}
\hline Grapes & $\begin{array}{l}\text { É um programa de desenvolvimento } \\
\text { matemático, voltado para a } \\
\text { plotagem de gráficos de funções. } \\
\text { Sua funcionalidade diversificada } \\
\text { possibilita a utilização do programa } \\
\text { para aplicações básicas de } \\
\text { matemática de ensino fundamental } \\
\text { e médio, e até mesmo para tópicos } \\
\text { de cálculo avançado, como a } \\
\text { plotagem de séries de Fourier, que } \\
\text { decompõem uma função periódica } \\
\text { através de senos e cossenos. }\end{array}$ & $\begin{array}{l}\text { Uma característica } \\
\text { interessante deste programa é } \\
\text { a possibilidade de se alterar } \\
\text { parâmetros matemáticos em } \\
\text { tempo real. Um gráfico } \\
\text { plotado pode ser alterado } \\
\text { passo a passo, até se obter a } \\
\text { função desejada, da forma } \\
\text { desejada. }\end{array}$ & $\begin{array}{l}\text { Se o objetivo é um } \\
\text { programa para } \\
\text { desenvolvimento de } \\
\text { ferramentas matemáticas } \\
\text { complexas, provavelmente } \\
\text { o Grapes não será } \\
\text { suficiente ou adequado. }\end{array}$ \\
\hline $\begin{array}{l}\text { SpeQ } \\
\text { Mathematics }\end{array}$ & $\begin{array}{l}\text { Possui recursos para funções, } \\
\text { operações matemáticas e geração de } \\
\text { gráficos. O programa foi } \\
\text { desenvolvido para desde os cálculos } \\
\text { mais básicos, até as operações } \\
\text { compostas por variáveis extensas e } \\
\text { funções bastante complexas. Dessa } \\
\text { forma, pode ser usado por } \\
\text { profissionais ou estudantes. Com } \\
\text { cerca de cem constantes e sessenta } \\
\text { funções incluídas, o programa é útil } \\
\text { nas áreas de aritmética, números } \\
\text { complexos, integrais, probabilidade, } \\
\text { sistemas numéricos, estatística e até } \\
\text { trigonometria. Pode-se aplicar cores } \\
\text { aos seus cálculos para facilitar a sua } \\
\text { visualização e, posteriormente, } \\
\text { salvar todos os seus resultados. }\end{array}$ & $\begin{array}{l}\text { SpeQ Mathematics é um } \\
\text { programa auxiliar para quem } \\
\text { trabalha com cálculos } \\
\text { matemáticos e necessita de } \\
\text { uma ferramenta precisa e } \\
\text { muito prática, que resulte } \\
\text { numa importante economia de } \\
\text { tempo. SpeQ é compacto e } \\
\text { tem uma interface muito fácil } \\
\text { de usar, baseada em } \\
\text { informações que podem ser } \\
\text { adicionadas, editadas e } \\
\text { executadas para gerar os } \\
\text { respectivos resultados. Podem } \\
\text { ser definidas as variáveis e as } \\
\text { funções e, depois, pode-se } \\
\text { gerar os gráficos } \\
\text { correspondentes. }\end{array}$ & \\
\hline $\begin{array}{l}\text { Math } \\
\text { Mechanixs }\end{array}$ & $\begin{array}{l}\text { Inclui um editor para gráficos, } \\
\text { criando-se vários modelos e } \\
\text { visualizando tudo no computador. É } \\
\text { possível exportar essas imagens } \\
\text { para outras aplicações. A edição } \\
\text { destes gráficos possibilita a } \\
\text { alteração de cores de cores de } \\
\text { fundo, dos dados, textos e áreas, } \\
\text { bem como se pode determinar os } \\
\text { tipos de gráficos a serem utilizados, } \\
\text { como 2D, 3D, em linha, setores, } \\
\text { barras, áreas, entre outros. }\end{array}$ & $\begin{array}{l}\text { O programa traz um editor } \\
\text { matemático, permitindo aos } \\
\text { usuários digitarem as } \\
\text { expressões matemáticas a } \\
\text { serem solucionadas. A } \\
\text { interface de Math Mechanixs } \\
\text { possibilita o trabalho com } \\
\text { vários documentos } \\
\text { simultaneamente, e todos } \\
\text { ficam minimizados na Barra } \\
\text { de Tarefas do programa. }\end{array}$ & $\begin{array}{l}\text { É um programa um pouco } \\
\text { complicado de usar com } \\
\text { muitas tabelas sem a } \\
\text { possibilidade de se calcular } \\
\text { de maneira convencional } \\
\text { algumas equações. }\end{array}$ \\
\hline
\end{tabular}

A partir desses elementos, o software escolhido foi o Winplot. Foi selecionado por ser gratuito, de simples utilização, seus menus são de fácil entendimento e apresenta ajuda em todas as partes do programa. O tamanho do arquivo é muito pequeno, menos de 1,9 $\mathrm{Kb}$, de fácil instalação e roda em ambiente Windows. É sempre atualizado e possui versão em português. O software Winplot foi projetado para reconhecer a maioria das operações matemáticas e funções elementares. Trabalha com duas e três dimensões, com equações explícitas, implícitas, paramétricas e polares. Cria pontos, segmento e reta, equações recursivas, diferenciais e polinomiais, cilindros, esferas entre outros. Ainda, permite troca de cores, espessura, faz aproximações, anotações e permite salvar as produções, para possível consulta ou alteração. Localiza com facilidade as raízes das funções, as interseções das retas, calcula integrais e apresenta as coordenadas de cada ponto que se procura. Pela praticidade e opções que oferece, pode ser utilizado por professores do Ensino Fundamental, Médio e Superior. A cada comando aparece um menu com diversas opções, permitindo que se crie exemplos, faça modificações e construções. Os demais softwares foram descartados, devido à dificuldade de se trabalhar com a transformação de escalas.

\subsection{Preparação das aulas e atividades}

A preocupação em preparar aulas contextualizadas para o ensino superior permitiu que fossem feitas reflexões sobre o conceito de contextualização. Tufano (2001) esclarece que: 
Contextualizar: ato de colocar no contexto. Do latim contextu. Colocar alguém a par de algo, alguma coisa, uma ação premeditada para situar um indivíduo em um lugar no tempo e no espaço desejado, encadear idéias em um escrito, constituir o texto no seu todo, argumentar. A contextualização do ensino de matemática é bastante valorizada na medida em que permite ao aluno perceber que "sua realidade e a realidade de seu meio é o cenário onde se aplicam os fundamentos apreendidos em outros ambientes ou em outros tempos.

Ainda sobre o conceito de contextualização, para Fonseca (1995), contextualizar não é abolir a técnica e a compreensão, mas ultrapassar esses aspectos e entender fatores externos aos que normalmente são explicitados na escola de modo a que os conteúdos matemáticos possam ser compreendidos dentro do panorama histórico, social e cultural que o constituíram. Com as Revisões Sistemáticas da teoria, dos softwares e da escolha do Winplot, foi montada uma aula sobre função afim, que foi preparada com intuito de motivar e envolver o aluno no processo de desenvolvimento das atividades, para isso, elaborar atividades no contexto dos alunos foi um possível caminho.

\subsection{Aplicação da atividade}

A aula foi ministrada no primeiro período de curso de Engenharia da Computação, com o objetivo de analisar se o software escolhido contribuiria para uma aprendizagem efetiva, com sentido e significado aos alunos, uma vez que os mesmos ainda não tiveram o estudo da disciplina que envolve a temática da função. A turma de Engenharia da Computação é composta de 35 (trinta e cinco) alunos.

Como o objetivo da pesquisa é verificar se o uso de ferramentas computacionais auxilia na aprendizagem de conteúdos matemáticos, os alunos foram divididos em duas turmas, sendo que a metade da turma ficou em sala com um professor-pesquisador e a outra metade foi ao laboratório de informática com outro professor-pesquisador.

A turma foi dividida por sorteio. Foram distribuídas cartas de cores vermelhas e pretas, escolhidas aleatoriamente pelos alunos. Alunos que tiraram a carta vermelha ficaram na aula expositiva em sala, os que tiraram carta preta foram para o laboratório de informática da instituição. As duas turmas divididas receberam a mesma aula, sendo que os alunos que ficaram em sala de aula, realizaram as atividades propostas manuscritas e os alunos que foram para o laboratório de informática, realizaram as atividades utilizando o software Winplot. Foi ministrada uma aula, dividida em dois momentos: Teórica e Contextualizada, além de uma avaliação. Foi feito, a partir da análise dos resultados obtidos das avaliações, uma reflexão sobre a utilização do software e sua contribuição para o ensino aprendizagem da função afim.

No dia proposto para a realização da atividade, chegou-se à sala de aula, a pesquisa foi apresentada aos alunos ali presentes e foram distribuídos o Termo de Consentimento e Participação. Após essa apresentação, 14 alunos assinaram o termo e ajudaram na pesquisa. Em sala com os alunos, foi ministrada a aula por um pesquisador, a aula no laboratório foi ministrada por outro pesquisador. A avaliação foi analisada com um estudo estatístico, para obter os resultados da pesquisa.

\section{Resultados e Discussão}

O objetivo principal deste estudo experimental é verificar se existem diferenças significativas entre a utilização de ferramentas computacionais no processo de ensino de ensino e aprendizagem de cálculo, e a não utilização destas ferramentas, em relação ao rendimento dos estudantes e ao tempo gasto pelos alunos para resolução das atividades propostas. Nesse sentido, foi conduzido um estudo experimental envolvendo 12 participantes (2 não completaram as atividades), que foram divididos em dois grupos, com o objetivo de aplicar quatro atividades envolvendo o conceito de função afim. Embora o número de alunos seja relativamente pequeno, trata-se da realidade do número de alunos da turma em questão, e 
foram utilizadas técnicas estatísticas apropriadas para essa quantidade de participantes durante a análise dos dados.

O primeiro grupo (SALA) foi composto por 7 participantes e as atividades propostas foram executadas de forma expositiva em sala de aula. O segundo grupo (LAB) foi composto por 5 participantes e as atividades propostas foram executadas com o auxílio do software gratuito Winplot. Após a aplicação e correção das atividades, os dados foram tabulados conforme apresentado na Tabela 3 . Os dados foram analisados utilizando-se o programa estatístico Minitab (2015), versão 16.2.2.

Tabela 2. Dados da pesquisa

\begin{tabular}{|c|c|c|c|}
\hline GRUPO & PARTICIPANTE & TEMPO (MIN) & Rendimento (PONTOS) \\
\hline SALA & S1 & 36 & 88 \\
\hline SALA & S2 & 22 & 0 \\
\hline SALA & S3 & 20 & 20 \\
\hline SALA & S4 & 25 & 26,5 \\
\hline SALA & S5 & 28 & 43,5 \\
\hline SALA & S6 & 29 & 22 \\
\hline SALA & S7 & 32 & 12 \\
\hline LAB & L1 & 8 & 81 \\
\hline LAB & L2 & 13 & 84 \\
\hline LAB & L3 & 56 & 25 \\
\hline LAB & L4 & 10 & 21 \\
\hline LAB & L5 & 17 & \\
\hline
\end{tabular}

\subsection{Análise da variável "Rendimento"}

Esta variável representa o total de pontos obtidos pelos estudantes na realização de uma atividade proposta.

\subsection{Teste de Hipótese}

Há diferença entre os rendimentos dos alunos na resolução das atividades propostas para os alunos que trabalharam em sala de aula (SALA) e os alunos que trabalharam no laboratório de informática utilizando o software Winplot (LAB)?

- $\mathrm{H}_{0 \text { : }} \mathrm{o}$ rendimento médio para a resolução da atividade em sala é igual ao rendimento médio de resolução das atividades no laboratório de informática com auxílio do software Winplot.

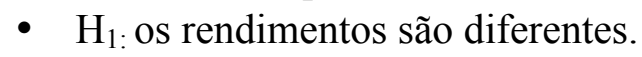

Nível de significância $\alpha=5 \%$

\subsection{Verificação dos pressupostos de normalidade e homocedasticidade}

a) Teste de Normalidade da variável "Rendimento":

Teste utilizado: Teste de normalidade de Anderson-Darling

- $\mathrm{H}_{0}$ : Os dados seguem a distribuição normal.

- $\mathrm{H}_{1}$ : Os dados não seguem a distribuição normal

A Figura 1 apresenta a análise da normalidade dos rendimentos dos alunos que fizeram a atividade em sala de aula, sem auxílio da ferramenta computacional. Observa-se que o $p$-value é igual a 0,132 , ou seja, $13,2 \%$. Como esse valor é maior que o nível de significância de $5 \%$ estabelecido, não rejeita-se a hipótese nula e pode-se dizer que os rendimentos dos alunos do grupo SALA seguem a distribuição normal.

Além disso, a Figura 2 apresenta a análise da normalidade do rendimento do grupo de alunos que fizeram a atividade no laboratório de informática, com auxílio do software Winplot. Observa-se que o $p$-value é igual a 0,159 , ou seja, 15,9\%. Como esse valor é maior que o nível de significância de 5\% estabelecido, não rejeita-se a hipótese nula e pode-se dizer que os rendimentos dos alunos do grupo LAB seguem a distribuição normal. 


\section{8}

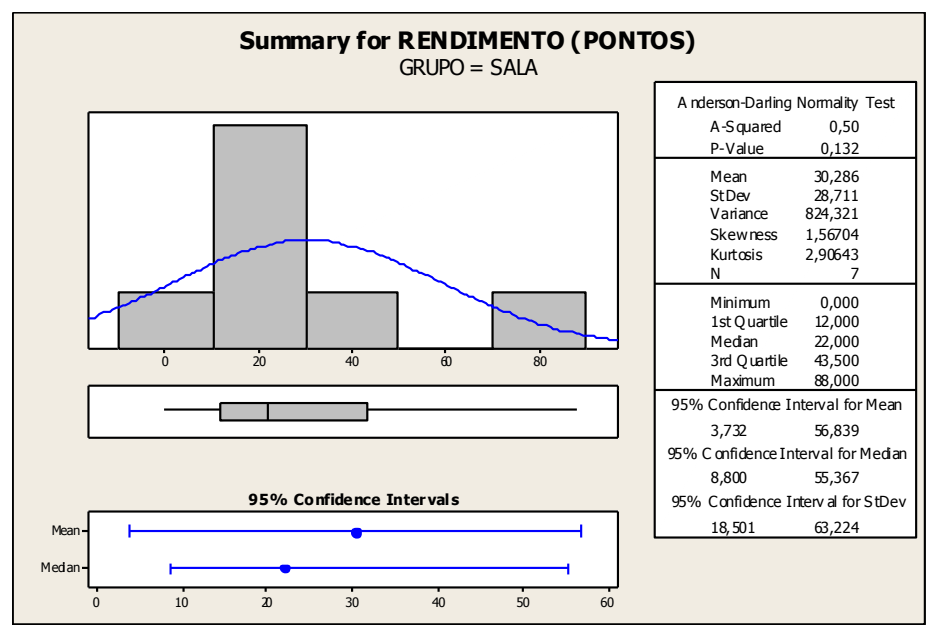

Figura 1. Teste de normalidade do grupo SALA

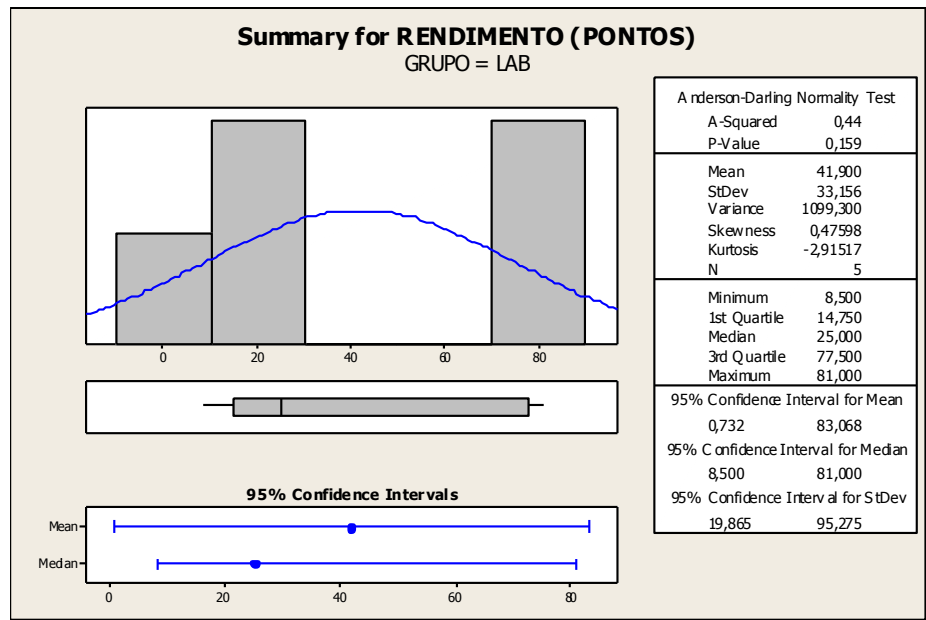

Figura 2. Teste de normalidade do grupo LAB

\section{b) Verificação da homocedasticidade (igualdade de variâncias):}

Teste utilizado: Teste de homocedasticidade de Levene

- $\mathrm{H}_{0}$ : Os dados são homocedásticos

- $\mathrm{H}_{1}$ : Os dados não são homocedásticos

A Figura 3 apresenta o resultado do teste de Levene para análise da igualdade de variâncias. Observa-se que o $p$-value é igual a 0,627 , ou seja, $62,7 \%$. Como esse valor é maior que o nível de significância de 5\% estabelecido, não rejeita-se a hipótese nula e pode-se dizer que os rendimentos dos alunos são homocedásticos, ou seja, as variâncias são iguais.

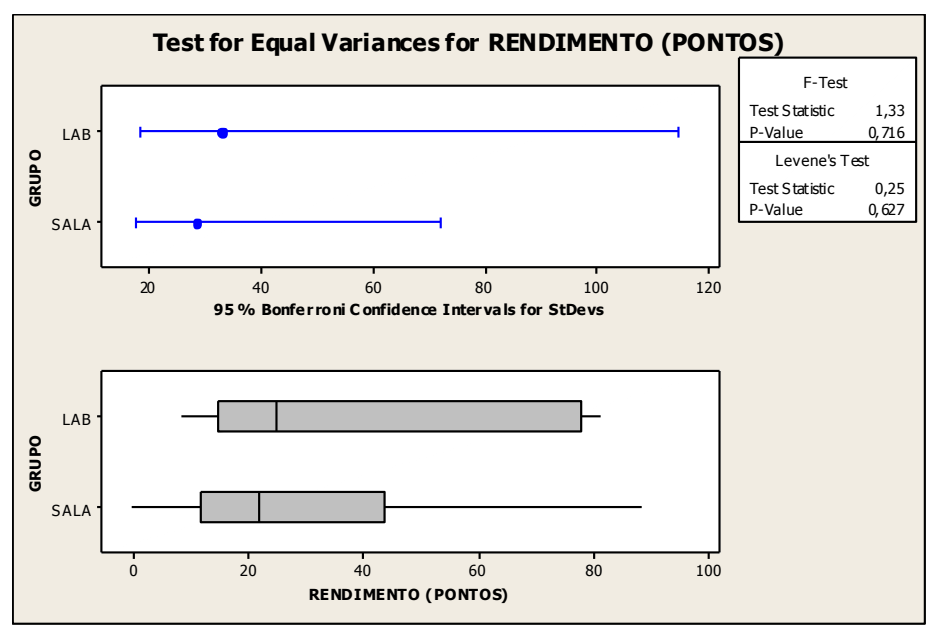

Figura 3. Teste de Homocedasticidade 


\subsection{Aplicação do teste estatístico}

As duas amostras são independentes (já que nenhum aluno participou dos dois grupos simultaneamente), os dados são quantitativos e seguem a distribuição normal, a variância populacional é desconhecida, mas sabe-se que a variância dos dois grupos são iguais.

Satisfeitos os pressuposto de normalidade e homocedasticidade, pode-se proceder com a análise de comparação das médias das duas amostras, utilizando um método estatístico paramétrico, gerando um novo teste de hipóteses, a um nível de significância de 5\%. Pode-se então utilizar o teste $T$ de Student, para comparar médias de duas amostras independentes:

- $\mathrm{H}_{0}$ : os rendimentos médios dos alunos que fizeram as atividades em sala de aula são iguais aos rendimentos médios dos alunos que fizeram as atividades no laboratório de informática, com auxilio do software gráfico Winplot.

- $\mathrm{H}_{1}$ : os rendimentos médios dos alunos que fizeram as atividades em sala de aula não são iguais aos rendimentos médios dos alunos que fizeram as atividades no laboratório de informática, com auxilio do software gráfico Winplot.

A Figura 4 apresenta o resultado da comparação das médias utilizando o teste $T$ de Student. Como obteve-se um $p$-value $=0,531$, ou seja, 53,1\%, maior que o nível de significância de $5 \%$ estabelecido, não se rejeita a hipótese nula, ou seja, não há diferença estatisticamente significantiva entre os rendimentos médios dos alunos que fizeram as atividades em sala de aula e os alunos que fizeram as atividades no laboratório de informática, com auxílio do programa gráfico Winplot. Dessa forma, não se pode afirmar que a utilização do software provocou alguma influência no desenvolvimento das atividades propostas. Novos estudos experimentais devem ser conduzidos para confirmar essa situação.

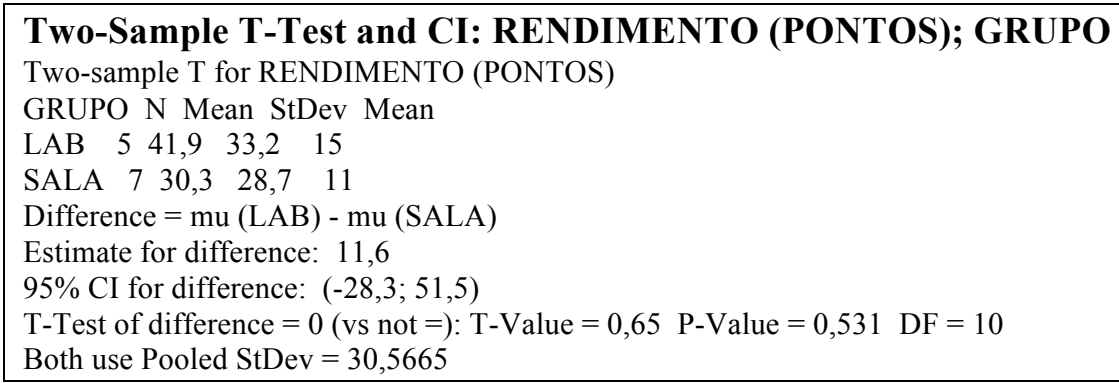

Figura 4. Teste de comparação de médias

\section{Conclusão}

A partir da Revisão Sistemática da Literatura realizada, pôde-se ter uma compreensão melhor do tema em estudo, através dos trabalhos publicados sobre o assunto. Pode-se perceber, através do resultado da revisão, que a área de ferramentas computacionais é promissora e vem sendo claramente explorada. Apesar de se tratar de uma vasta área de pesquisa com potencialidades em produções científicas, preliminarmente nota-se que a sociedade moderna está definida e estruturada pela tecnologia, mas o sistema escolar ainda se encontra tradicionalmente conservador, isto é, isentando essa influência. Ficou claro nas pesquisas outra limitação em que o professor ainda resiste a mudanças, adotar uma postura de orientador da construção do conhecimento em substituição à metodologia do doador da transmissão do saber.

Muitos softwares e novas metodologias para o ensino do Cálculo foram apresentados nos artigos selecionados, o que amplia uma área de pesquisa buscando estratégias utilizadas com o uso do computador e suas ferramentas para o ensino de cálculo.

Devido ao número pequeno de participantes na pesquisa, não é possível concluir de forma definitiva sobre a eficácia da utilização do uso de software na interferência no rendimento do aluno, porém, cabe ressaltar que o objetivo dessa pesquisa não é apenas pontuar resultados, mas sim expor um planejamento de estudo que, posteriormente com 
condições amostrais ideais podem, de fato, consolidar a pesquisa em termos de resultados, utilizando-se de metodologia para seleção de estudos, e aplicação de métodos estatísticos adequados.

Como trabalhos futuros, deverão ser realizados novos estudos experimentais com outros grupos de alunos, de forma a confrontar os resultados obtidos na tentativa de generalizá-los.

Pretende-se ainda contribuir com a comunidade científica para futuros trabalhos com as descrições das etapas exercidas nesta pesquisa.

\section{Referências Bibliográficas}

AMORIM, F. V. Experiência de atividades para o cálculo diferencial e integral com o software Geogebra. 2011.186 f. Dissertação (Mestrado Profissional em Ensino de Ciências Naturais e Matemática) - Universidade Federal do Rio Grande do Norte, Natal, 2011.

BORBA, M. C.; VILLARREAL, M. V. Humans-With-Media and the Reorganization of Mathematical Thinking: information and communication technologies, modeling, experimentation and visualization. v. 39, New York: Springer, 2005.

FONSECA, M. C. F. R. Por que ensinar Matemática. Presença Pedagógica, Belo Horizonte, v.1, n. 6, mar/abril, 1995.

GEOGEBRA. Disponível em: <www.geogebra.org/> Acesso em: 30 out. 2015.

GONÇALVES, J. L. Avaliação de softwares matemáticos quanto a sua funcionalidade e tipo de licença para uso em sala de aula. Revista de ensino de Ciências e Matemática. v. 1, n. 1. 2010 .

GRAPES. Disponível em: <www.criced.tsukuba.ac.jp/grapes>. Acesso em: 30 out. 2015.

KITCHENHAM, B. Procedures for Performing Systematic Reviews, Keele technical report SE0401 and NICTA technical report 0400011T.1, 2004.

MATH MECHANIXS. Disponível em: <www.mathmechanixs.com>. Acesso em: 30 out. 2015.

MINITAB, versão 17. Disponível em: <www.minitab.com.br>. Acesso em: 30 out. 2015.

MiSKulin, R. G. S.; AMORIN, J. A.; SILVA, M. R. C. As Possibilidades Pedagógicas do Ambiente computacional TELEDUC na Exploração, Disseminação e Representação de Conceitos Matemáticos. In.: BARBOSA, R. M. (Org.). Ambientes Virtuais de Aprendizagem. Porto Alegre: Artmed, 2005.

ROCHA, M. D. Desenvolvendo Atividades Computacionais na Disciplina Cálculo Integral e Diferencial I: Estudo de uma Proposta de Ensino Pautada na Articulação entre a Visualização e a Experimentação. Universidade Federal de Ouro Preto. Programa de Pós-Graduação em Educação Matemática, 2010.

SCHELLER, M.; VIALI, L.; LAHM, R. A. A Aprendizagem no Contexto das Tecnologias: Uma Reflexão para os Dias Atuais. Revista Renote - Novas Tecnologias na Educação. v. 12, n. 2, 2014.

SPEQ MATHEMATICS. Disponível em: <www.speqmath.com>. Acesso em: 30 out. 2015.

TUFANO, W. Contextualização. In: FAZENDA, Ivani C. Dicionário em Construção: Interdisciplinaridade. São Paulo: Cortez, 2001.

WINPLOT. Disponível em: <www.winplot.softonic.com.br>. Acesso em: 30 out. 2015. 